Revista

Ibero-Americana

de Estratégıa

\title{
EMPREENDEDORISMO E INTERNACIONALIZAÇÃO: UM CASO NO SETOR DE EVENTOS DE GESTÃO
}

\author{
ENTREPRENEURSHIP AND INTERNATIONALIZATION: A CASE STUDY IN \\ MANAGEMENT EVENTS INDUSTRY
}

\section{EL ESPÍRITU EMPRESARIAL Y INTERNACIONALIZACIÓN: UN CASO EN EL SECTOR DE EVENTOS DE GESTIÓN}

\section{Belmiro do Nascimento João}

Doutor em Comunicação e Semiótica pela Pontifícia Universidade Católica de São Paulo - PUC/SP Professor da Pontifícia Universidade Católica de São Paulo - PUC/SP E-mail: bjoao@pucsp.br (Brasil)

\section{João Gonçalves Monteiro Jr}

Doutorando em Educação pela Pontifícia Universidade Católica de São Paulo - PUC/SP

Professor da Pontifícia Universidade Católica de São Paulo - PUC/SP

E-mail: jgmonteiro@pucsp.br (Brasil)

\section{Aparecida Honório Dias}

Mestrado em Gestão de Negócios pela Pontifícia Universidade Católica de São Paulo - PUC/SP Coordenadora do curso de Administração e Organização de Eventos do Centro Universitário SENAC

E-mail: aparecida.dias@terra.com.br (Brasil)

\section{Fabrício César Bastos}

Mestrado em Administração pela Pontifícia Universidade Católica de São Paulo - PUC/SP

Professor da Pontifícia Universidade Católica de São Paulo - PUC/SP

E-mail: fabricb@yahoo.com.br (Brasil) 


\title{
EMPREENDEDORISMO E INTERNACIONALIZAÇÃO: UM CASO NO SETOR DE EVENTOS DE GESTÃO
}

\section{RESUMO}

Esta pesquisa trata do processo de internacionalização de uma empresa de serviços com origem em três empreendedores brasileiros. O objetivo, a partir de um estudo de caso único, foi identificar as características de empreendedorismo internacional, seu alinhamento com as teorias de internacionalização, como a escola nórdica de negócios internacionais, os modos de entrada e o desenvolvimento de competências essenciais que possibilitaram seu sucesso global. Como resultado, são destacados: 1) o papel empreendedor de seus fundadores, e "re-fundadores", no Brasil e na Argentina; 2) a reputação como competência essencial; 3) o papel crítico dos relacionamentos e das redes internacionais, envolvendo os gurus de gestão e CEOs; 4) a replicação de conhecimento dentro do HSM Group; 5) a HSM Group também segue a lógica incremental do Modelo de Uppsala, bem como apresenta a abordagem de redes.

Palavras-chave: Empreendedorismo; Internacionalização; Serviços; Reputação; Estratégia.

\section{ENTREPRENEURSHIP AND INTERNATIONALIZATION: A CASE STUDY IN MANAGEMENT EVENTS INDUSTRY}

\begin{abstract}
This research deals with the process of internationalization of a service company administered by three Brazilian entrepreneurs. The objective, based on a single case study, was to identify the characteristics of international entrepreneurship, its alignment with the theories of internationalization - as the Nordic school of international business - entry modes, and the development of core competence, which enabled its overall success. Within the results, it is highlighted: 1) the entrepreneurial role of its founders, and "re-founders", in Brazil and Argentina, 2) the reputation as a core competence, 3) the critical role of international relationships and networks, involving the management gurus and CEOs, 4) the replication of knowledge within the HSM Group, 5) The HSM Group also follows the logic of the Uppsala model of incremental internationalization and network approach.
\end{abstract}

Keywords: Entrepreneurship; Internationalization; Services; Reputation; Strategy.

Revista Ibero-Americana de Estratégia - RIAE, São Paulo, v. 9, n. 1, p. 04-31, jan./abr. 2010. 


\section{EL ESPÍRITU EMPRESARIAL Y INTERNACIONALIZACIÓN: UN CASO EN EL SECTOR DE EVENTOS DE GESTIÓN}

\section{RESUMEN}

Esta investigación trata del proceso de internacionalización de una empresa de servicios con origen en tres emprendedores brasileños. El objetivo, a partir de un estudio de caso único, fue identificar las características del espíritu empresarial internacional, su alineación con las teorías de internacionalización, como la escuela nórdica de negocios internacionales, los modos de entrada y el desarrollo de las competencias esenciales que posibilitaron su éxito global. Como resultado se destacan: 1) el papel emprendedor de sus fundadores, y re-fundadores, en Brasil y en Argentina; 2) la reputación como competencia esencial; 3) el papel fundamental de las relaciones y de las redes internacionales, involucrando a los gurús de la gestión y CEOs; 4) la replicación de conocimiento dentro del HSM Group; 5) la HSM Group también sigue la lógica gradual del Modelo de Uppsala, así como presenta el abordaje de redes.

Palabras-clave: Espíritu Empresarial; Internacionalización; Servicios; Reputación; Estrategia.

Revista Ibero-Americana de Estratégia - RIAE, São Paulo, v. 9, n. 1, p. 04-31, jan./abr. 2010. 


\title{
1 INTRODUÇÃO
}

Para a presente pesquisa tem-se uma gama de questões de partida que pode ser resumida da seguinte forma: como um grupo de empreendedores deu origem a uma empresa internacional no setor de eventos de gestão e quais competências empreendedoras e de reputação foram desenvolvidas para ser bem-sucedida internacionalmente em uma indústria complexa como a de serviços.

A importância do tema, empreendedorismo e internacionalização, pode ser vista em obras como as de Oviatt e McDougall (2006), Zahra e George (2002) Hitt, Ireland, Camp e Sexton (2002) e Dana (2006). Mark Casson, na introdução da obra de Dana (2006), diz que o empreendedorismo e os negócios internacionais são temas que se têm mantido separados durante muito tempo, desse modo, o estudo de empreendedorismo internacional prospera no cruzamento fértil de ideias entre esses campos sendo, desse modo, uma área dinâmica de pesquisa. Casson (1997) também trabalha com o conceito de redes de empreendedores em negócios internacionais.

Para um entendimento do mercado de gestão, tem-se, segundo Wood Jr. e Paula (2002) que:

\begin{abstract}
Durante os anos 80 e 90, a publicação de revistas e livros de negócios se transformou em um negócio próspero. O contexto, real ou imaginário, de turbulência e competição contribuiu para a geração de uma literatura voltada para as questões, ansiedades e dilemas dos profissionais da administração: a literatura de pop-management. [...] Por seu alcance e apelo popular, tal literatura vem desempenhando um papel importante na disseminação de novas ideias e tecnologias gerenciais, além de influenciar, podemos especular, a construção das agendas dos executivos e dos pesquisadores da administração. (p.1).
\end{abstract}

Essa literatura surgiu com o best-seller de Peters e Waterman (1982), que revolucionou não somente o mercado editorial (livros, revistas de negócios, vídeos), mas também criou a figura dos "gurus" da gestão. Ao longo dos anos, o mesmo aconteceu com diversos autores, como Hammer e Champy (1994), com sua concepção a respeito de reengenharia e também com vários CEO (Chief Executive Officer), como Jack Welch da General Electric, que passaram a ter voz ativa em palestras pelo mundo. Dentro desse cenário, surge o insight para o desenvolvimento desta pesquisa a partir de uma empresa de eventos, a HSM, que soube detectar a mudança no âmbito da gestão da nova “cultura de negócios”, bem como atrair os agentes de legitimação (Wood Jr. \& Paula, 2002) para seu quadro de palestrantes e desenvolver reputação que lhe dá credibilidade para o processo de internacionalização.

A motivação se dá por ser uma multinacional, de origem brasileira, cujo nome HSM, iniciais de seus fundadores e empreendedores (Harry Ufer, José Salibi Neto e Marina Ufer) e por atuar em um setor complexo no qual o Brasil não tem tradição na internacionalização.

Revista Ibero-Americana de Estratégia - RIAE, São Paulo, v. 9, n. 1, p. 04-31, jan./abr. 2010. 
Outro fato é o de não haver estudos sobre o HSM Group publicados (Google Acadêmico, 2007) e de estar nas mãos de grandes investidores entre os quais o J.P.Morgan e o Credit Suisse First Boston (CSFB).

O artigo está assim distribuído, além desta introdução. Uma revisão teórica que aborda os temas do empreendedorismo internacional, do desenvolvimento de competências essenciais (reputação) das teorias de internacionalização e da internacionalização do setor de serviços, além de uma caracterização do setor de serviços. Os procedimentos metodológicos são apresentados, bem como o caso HSM e sua análise. Complementando a pesquisa, as conclusões e referências empregadas.

\section{REFERENCIAL TEÓRICO}

Para o desenvolvimento da presente pesquisa procurou-se explorar as convergências entre o processo de internacionalização das empresas e a atividade empreendedora, suas competências essenciais, destacando-se a reputação, bem como as teorias de internacionalização, do setor de serviços e, especificamente, de eventos.

\subsection{O EMPREENDEDORISMO E A INTERNACIONALIZAÇÃO}

Segundo McDougall e Oviatt (2000), o termo empreendedorismo internacional, ou "international entrepreneurship", data do final da década de 80, quando foram lançadas as bases para a compreensão do fenômeno. À época, empreendedorismo internacional era compreendido como a simples existência de empreendimentos de nível internacional. Os primeiros estudos sobre o conceito focaram basicamente empresas que se internacionalizam desde seu surgimento, ou seja, que realizam atividades internacionais desde a sua fundação, e é coincidente com o surgimento das empresas Born Globals (Knight \& Cavusgil, 1996). Com o passar dos anos, a percepção de empreendedorismo internacional vai sendo ampliada e refinada. Na década de 90, Ricks e Wright (1994) afirmam que mesmo empreendedores com visão mais focada em seu local deveriam estar atentos à concorrência internacional, em vista da possibilidade de empresas que atuam internacionalmente passarem a concorrer no mercado local.

McDougall, Shane e Oviatt (1994) também acompanharam o aprofundamento conceitual sobre empreendedorismo internacional. Esses autores definiram empreendedorismo internacional

Revista Ibero-Americana de Estratégia - RIAE, São Paulo, v. 9, n. 1, p. 04-31, jan./abr. 2010. 
como "uma organização comercial que, desde sua criação, obtém significante vantagem competitiva no uso de recursos e a venda de produtos finais em vários países" (McDougall, Shane \& Oviatt, 1994). Mais a frente, McDougall e Oviatt (2000) ampliam ainda mais suas concepções sobre a modalidade internacional de empreendedorismo, definindo-a como "a combinação de inovação, proatividade e aversão ao risco que cruza ou é comparado através das fronteiras nacionais e planeja criar valor em negócios da organização" (p.6). . Nesta concepção defendida pelos autores, a idade, o tamanho e a característica de uma organização não são excludentes para enquadrar uma empresa como empreendedora internacional. Ainda segundo os autores, ficam excluídas da concepção de empreendedorismo internacional as organizações governamentais e aquelas sem finalidade lucrativa. Assim, para organizações empresariais típicas, o tamanho da empresa e seu tempo de existência não interferem na possibilidade de haver um comportamento empreendedor internacional por parte de uma organização. Tal concepção também contribui para a derrubada de um mito em empreendedorismo: o de que as empresas bem estabelecidas possuem aversão ao risco e não são inovadoras (Zahra \& George, 2002).

No olhar de Yeung (2002), empreendedorismo internacional supõe que o empreendedor deve ser dotado de controle dos recursos, capacidade de controle das estratégias e habilidades para criar e explorar oportunidades em diferentes países. Essas características, espelhando a necessidade de inovação e a aversão ao risco necessário às empresas para que possam alavancar suas operações internacionais, torna o empreendedorismo internacional um atrativo e singular campo de pesquisa (Zahra \& George, 2002). Pesquisas tradicionais como a de Goerzen e Makino (2007) apresentam estudo sobre a internacionalização sequencial na indústria de serviços (trading companies) japonesas destacando um foco na questão do investimento no exterior, mas outros como o de Acs, Dana e Jones (2003) apresentam a ideia de que o empreendedorismo não vem somente das grandes corporações multinacionais, mas de organizações de diversos países e porte. Mesmo havendo interesse crescente pelo fenômeno do empreendedorismo internacional, Knight, Rialp e Rialp (2005) observam que este ainda está distante de se tornar bem caracterizado, ou seja, com contornos bem definidos e compreendido.

Melhor caracterizando uma definição de empreendedor, este é tido como, segundo Dornelas (2007), por uma pessoa que faz acontecer, e se antecipa aos fatos, e com isso, tem uma visão futura da organização. Ou ainda em Hitt. Hoskisson e Ireland (2002) “empreendedores sentem as oportunidades antes dos outros e assumem riscos da incerteza de se estabelecerem novos mercados, desenvolver novos produtos ou formarem processos ou mecanismos de prestação de serviços inovadores" (p.526).

Revista Ibero-Americana de Estratégia - RIAE, São Paulo, v. 9, n. 1, p. 04-31, jan./abr. 2010. 
Estas ou outras definições ou caracterizações de empreendedorismo, possuem um eixo comum de aspectos referentes ao empreendedor, como a iniciativa para criar um negócio e ter paixão por ele; utilização criativa de recursos disponíveis; aceitação de riscos e da possibilidade de fracasso. Características como correr riscos, independência /autonomia, ser inovador e realização destacam-se na literatura de negócios (Dornelas, 2007).

A literatura nacional da área se estende por conhecimentos referentes a perfil de empreendedores, gestão de empresas, etapas e planos de negócios, estratégias e projetos, competências, empreendedorismo corporativo, entre outros (Degen, 1989; Dornelas, 2003, 2007; Maximiano, 2007). Tais recortes da caracterização do empreendedorismo auxiliam na compreensão de fenômenos empresariais, como no caso aqui estudado, enfocado também pela ótica da internacionalização.

Num olhar estrito, focado no empreendedorismo internacional, Andersson (2000), representante da Escola Nórdica de Negócios Internacionais, afirma existir um peso significativo no papel de empreendedores como força motriz da internacionalização. Estudo do autor revela a importância limitada de se analisar a empresa e os fatores externos do processo de internacionalização no caso dos indivíduos não serem incluídos na análise. $\mathrm{O}$ autor entende ser a figura do empreendedor a de ter habilidade em lidar com diferentes combinações, desenvolver essas combinações, perceber formas de ação e conseguir convencer terceiros a investir em seus projetos e todas dentro de um tempo apropriado. Ainda para o autor o conceito de empreendedor vincula conceitos macroestruturais e a empresa com conceitos processuais de estratégia e de internacionalização. Nesse sentido, o processo de internacionalização ocorre a partir da ação empreendedora de um indivíduo, o que o torna protagonista desse processo, já que não seria suficiente dispor de recursos e caminhar em direção a oportunidades se a internacionalização não fosse desejada e efetivamente realizada por pessoas dotadas de perfil empreendedor.

Andersson (2000) classifica os empreendedores internacionais em três perfis de executores da estratégia de internacionalização: o empreendedor técnico, o empreendedor de marketing e o empreendedor estrutural.

Os empreendedores técnicos trabalham para introduzir novos produtos ou novos métodos de produção, ou ainda para conquistar fontes de suprimento de matérias-primas ou de produtos. Operam com inovações técnicas, sendo seu principal foco a tecnologia, as atividades de produção e o desenvolvimento de produtos. A internacionalização é motivada não pelo interesse desse perfil de empreendedor, mas por um eventual pedido do exterior que pode levar à exportação ou ao

Revista Ibero-Americana de Estratégia - RIAE, São Paulo, v. 9, n. 1, p. 04-31, jan./abr. 2010. 
Empreendedorismo e Internacionalização: Um Caso no Setor de Eventos de Gestão

licenciamento. São atividades que normalmente não necessitam de recursos como investimento em uma subsidiária. A estrutura industrial típica para mercados com novos produtos é basicamente emergente ou em crescimento, e a escolha de mercados a serem trabalhados depende naturalmente de uma estratégia de international-pull, ou movida pela demanda.

Todavia, os empreendedores de marketing direcionam suas ações na abertura de novos mercados. Podem inovar, se empregarem novos métodos de marketing. O produto é visto de forma ampla, já que os canais de mercado e as marcas podem superar em importância o próprio produto físico. O mercado encontra-se normalmente em crescimento ou é emergente. Este empreendedor é proativo no processo de internacionalização, e escolhe normalmente modos de entrada que requer muitos recursos, tais como investimentos em novas plantas no exterior, como forma de penetrar rapidamente em novos mercados. Sua escolha de mercados não é necessariamente racional: preferências pessoais e redes de relacionamento pessoal podem influenciar a decisão. Sua estratégia pode ser denominada de estratégia de international push, ou movida pela oferta.

Já os empreendedores estruturais, agem voltados a uma nova organização de qualquer segmento industrial. Em geral, atuam em indústrias maduras. Implementam, por exemplo, a quebra ou a criação de uma situação de monopólio de mercado. Sua estratégia atende ao nível corporativo e raramente intervêm diretamente em assuntos operacionais.

Mediante a combinação de organizações novas, ideias de negócios são desenvolvidas e estes empreendedores empenham-se em reestruturar empresas e indústrias. Dessa perspectiva, a internacionalização não é algo isolado, como um objetivo independente, mas parte da estratégia total da firma. Como a maioria das indústrias maduras está internacionalizada, este tipo de empreendedor torna-se um importante ator internacional, dando preferência a aquisições e fusões para reduzir a capacidade das indústrias. A sua estratégia é também conhecida como estratégia internacional de reestruturação da indústria, ou movida pela transformação.

Conforme exposto, os diferentes tipos de empreendedores implementam diferentes estratégias internacionais. Segundo Andersson (2000), a perspectiva do empreendedorismo, propõe que os indivíduos que participam do processo de internacionalização são os fatores mais importantes na determinação e escolha do modo de entrada. Indivíduos em firmas que parecem similares e têm ambientes similares podem, assim, diferir em suas visões de internacionalização.

Revista Ibero-Americana de Estratégia - RIAE, São Paulo, v. 9, n. 1, p. 04-31, jan./abr. 2010. 


\subsection{A REPUTAÇÃO COMO COMPETÊNCIA ESSENCIAL}

A reputação, assim como a confiança e o comprometimento das organizações em alianças com parceiros internacionais, passa a ter destaque na literatura de internacionalização (Johansson \& Vahlne, 2009). O conceito inicial, vindo dos estudos de competência ganhou importância e passou a ser distinguida como uma característica única da organização. Competência é considerada frequentemente como um vínculo entre a aprendizagem, o conhecimento e a sua estratégia corporativa. Este vínculo intrínseco à habilidade de uma organização em implementar ou agir com outras organizações. Prahalad e Hamel (1990) incluem as habilidades técnicas e administrativas que permitem a organização sobreviver a qual denominam de "competências essenciais".

As competências essenciais, a longo prazo, transformam-se em vantagem competitiva pela habilidade em construir competências únicas e antecipar necessidades. A fonte de vantagem é a habilidade para consolidar tecnologias por toda a organização e conhecimentos de produção em competências. Competências essenciais constituem um aprendizado coletivo na organização, especialmente no modo de coordenar diversas habilidades de produção, harmonizar fluxos de tecnologia, a organização do trabalho e a entrega de valor (Prahalad \& Hamel, 1990).

Dada a dispersão do conhecimento e a incerteza do ambiente, a sua aquisição é um importante processo pelo qual gerentes identificam e absorvem o conhecimento relevante que está sendo criado. Fluxos de conhecimento na organização envolvendo a sede e operações globais passam a ter importância crescente em processos como os estudos de internacionalização de empresas (Kogut \& Zander, 1992). Construir colaboração é central para atualizar a base de conhecimento empresarial, seja por meio de parcerias, seja por meio de alianças ou aquisições de outras empresas e processos de aquisição interna de conhecimento.

A principal diferença entre a imagem corporativa e a reputação corporativa é que reputação é formada ao longo do tempo e a imagem, a curto prazo (Balmer \& Greyser, 2006). A construção de uma sólida reputação pode trazer uma vantagem distintiva e competitiva, contribuindo para os lucros da firma. Embora seja um recurso valioso (em muitos casos), a reputação corporativa não é uma garantia de sobrevivência ou de sucesso do negócio. Ao considerar percepções realizadas por uma organização, considera-se também a imagem/reputação da indústria, país de origem, marcas e produtos/serviços das empresas, bem como os das suas subsidiárias.

Fombrun e Van Riel (2003) descrevem reputação como algo que atrai, como um ímã, as pessoas para uma organização. Como se vê, uma organização com boa reputação atrai pessoas a

Revista Ibero-Americana de Estratégia - RIAE, São Paulo, v. 9, n. 1, p. 04-31, jan./abr. 2010. 
Empreendedorismo e Internacionalização: Um Caso no Setor de Eventos de Gestão

nela se engajarem, quer por meio da compra, quer investindo, trabalhando, etc. Em outras palavras, eles buscam ter uma relação com a organização. Uma relação com uma organização, a qual, por sua vez, para "adquirir uma reputação positiva, duradoura, resiliente requer gerentes que invistam fortemente na construção e manutenção de boas relações com os que constituem a empresa" (Fombrun, 1996, p. 57).

De acordo com Brønn (2007), a base da reputação de uma organização pode ser construída por meio de uma abordagem de relacionamento, pois, de fato, são as relações que determinam a reputação. Como implicação tem-se que os resultados indicam que a qualidade dos relacionamentos dos stakeholders de uma empresa pode impactar sua imagem perante o cliente. Logo, as empresas precisam alocar recursos para as estratégias corporativas, alinhadas com os diferentes stakeholders.

\subsection{INTERNACIONALIZAÇÃO DO SETOR DE SERVIÇOS}

As pesquisas sobre internacionalização têm sido tradicionalmente centradas em empresas de manufatura. A própria Escola Nórdica de Negócios Internacionais dizia que "Estudos revelam que o modelo do processo de internacionalização não é válido para o setor de serviços” (Johanson \& Vahlne, 1990, p. 15), mas na sua revisão (Johanson \& Vahlne, 2009) deixa claro o papel das redes de negócios, do aprendizado e da necessidade do desenvolvimento de confiança no processo de internacionalização. Contudo, na atualidade, há uma crescente atenção ao desenvolvimento de pesquisas em empresas de serviços. De acordo com Arvidsson (1997), esse aumento pode ser atribuído à importância maior desse setor nos principais países industrializados. No Brasil, alguns trabalhos recentes, espelham essa realidade (Cerqueira \& Quadros, 2003; Mazzola, 2006; Sacramento, 2005; Silva Neto \& Paula, 2005).

Nos anos 1980, viu-se uma elevação no Investimento Estrangeiro Direto (FDI) e o aumento na internacionalização de empresas de serviços. Esses fluxos de FDI representam mais de 50\% do total dos investimentos das principais nações durante as últimas décadas, aumentando, assim, a internacionalização do setor de serviços (The United Nations Centre on Transnational Corporations [UNCTC], 2007).

Como resultado desse aumento da atividade internacional no setor de serviços há necessidade de uma melhor compreensão do processo de internacionalização dessas empresas. No entanto, antes de analisar as várias correntes teóricas de internacionalização, é importante ter uma compreensão nas diferentes formas de atuação, da indústria de serviços em relação à indústria de transformação ou manufatureira.

Revista Ibero-Americana de Estratégia - RIAE, São Paulo, v. 9, n. 1, p. 04-31, jan./abr. 2010. 
A expressão "empresas de serviço" tem sido definida como aquelas que fornecem produtos por meio de processos de produção e vendas, que se caracterizam pelo alto grau de simultaneidade, perecibilidade ou intangibilidade (Arvidsson, 1997, Lovelock \& Wright, 2002). Buckley, Pass e Prescott (1992) também fornecem uma definição de serviços semelhantes, destacando suas características distintas como intangibilidade, inseparabilidade de produção e de consumo, heterogeneidade e perecibilidade.

É à luz dessas características que Chryssochoidis, Millar e Clegg (1997) observam que empresas de serviços não enfrentam as mesmas alternativas de investimento em seu processo de internacionalização que as empresas manufatureiras. Por conseguinte, a exportação de serviços finais, os acordos contratuais sobre serviços intermediários e a disponibilidade de serviços provenientes diretamente do estabelecimento estrangeiro são as três formas de envolvimento internacional detectadas na conexão com as empresas de serviços.

\subsubsection{O MAINSTREAM CONCEITUAL}

A partir do paradigma eclético tem-se o framework OLI (Ownership, Location, Internalization), em que as vantagens específicas de propriedade (ownership) para empresas de serviços são, geralmente, resultantes dos empregados, de conceitos específicos da firma ou sistemas de distribuição de serviços. Assim, as possibilidades de manter vantagens específicas de propriedade de longo prazo bem-sucedidas resultam de sistemas de serviços conceituais (Chryssochoidis et al., 1997).

$\mathrm{O}$ aspecto da internalização (internalization) do framework OLI é altamente aplicável no contexto da internacionalização de serviços. Isso ocorre porque a internalização é quase por definição feita em empresas de serviços quando estas escolhem iniciar atividades no exterior (Arvidsson, 1997). Mas há certos fatores que são relevantes na internalização de operações no exterior.

De um lado, empregados locais podem ser ativos importantes quando uma empresa de serviços tenta abordar clientes, uma vez que estes pertencem a essa mesma cultura. Há também maior probabilidade de registros de experiências estabelecidas que a empresa utilize como uma ponte para esse novo mercado. Agrega-se a isto a cooperação com empresas locais que fornecem legitimidade e boa reputação, contribuindo na construção de um rápido relacionamento com clientes e outros intervenientes neste novo ambiente.

Revista Ibero-Americana de Estratégia - RIAE, São Paulo, v. 9, n. 1, p. 04-31, jan./abr. 2010. 
Empreendedorismo e Internacionalização: Um Caso no Setor de Eventos de Gestão

Uma questão fundamental que uma empresa enfrenta no seu processo de internacionalização é o encontro com novas culturas e valores. Esta questão foi abordada por Johanson e Vahlne (1977), sob o termo "distância psíquica" e inclui fatores distintos, tais como as barreiras linguísticas, as diferenças no gosto do consumidor e as diferenças em termos de valor, atitudes e comportamentos entre outras. Para empresas de serviços a reputação ou o registro de experiência têm forte significado (Lowendahl, 2000), daí uma grande distância psíquica entre empresas de serviço e a de seus clientes ser suscetível a uma visão enviesada em relação aos registros de experiência e a criação de valor. Por último, uma grande distância psíquica poderia levar a empresa a fornecer um serviço menos satisfatório em razão de problemas de comunicação (Arvidsson, 1997).

Outro fator relevante que vincula o desenvolvimento de uma empresa à internacionalização é a influência das redes, como defendem Johanson e Sharma (1987) em um estudo com empresas suecas de serviços. Redes, arranjos cooperativos e relacionamentos pessoais são fatores frequentemente relevantes para a possibilidade de realização e de resultados das operações no exterior (Johanson \& Mattsson, 1988; Johansson \& Vahlne, 2009). Acredita-se que as redes são relativamente mais importantes para as empresas de serviço que para as empresas manufatureiras no relacionamento comprador-vendedor, uma vez que o serviço é frequentemente produzido por meio de interações pessoais entre comprador e vendedor. De acordo com Arvidsson (1997), a rede em torno de uma empresa de serviços e suas oportunidades resultantes são fatores que influenciam fortemente a internacionalização. As empresas de serviços podem entrar em redes mundiais com suas congêneres estrangeiras, com o intuito de obter ganhos de eficiência tanto de escala como de escopo.

\subsection{A EXPRESSÃO DO SETOR DE EVENTOS}

Conforme Britto e Fontes (2002), o conceito de evento remete além de um acontecimento de sucesso, ou a uma atividade de relações-públicas: "O evento é a soma de esforços e ações planejadas com o objetivo de alcançar resultados definidos junto ao seu público-alvo" (p. 20). A realização de um evento requer ação profissional, que envolve pesquisa, planejamento e processos de organização, coordenação, controle e implantação de um projeto, com o principal intuito de direcionar suas ações e atingir seu público-alvo com medidas concentradas e resultados projetados. Logo, o evento quando bem administrado ganha características não só de produto, mas de uma empresa. Uma empresa com vida própria, com sistema estrutural, funcional e de gerenciamento, justificando assim seu próprio planejamento, organização, direção e coordenação de tarefas (Britto \& Fontes, 2002).

Revista Ibero-Americana de Estratégia - RIAE, São Paulo, v. 9, n. 1, p. 04-31, jan./abr. 2010. 
A área de marketing promocional, da qual fazem parte os eventos, corresponde a um mercado de mais de 20 bilhões de reais em 2006, ou seja, mais de 50\% do total dos investimentos em comunicação e marketing, conforme levantamentos realizados pela Associação de Marketing Promocional [Ampro] (2008) para o mercado brasileiro, sendo seu orçamento (budget) promocional hoje superior às verbas de publicidade e propaganda. O setor de eventos é representado por empresas organizadoras, promotoras e prestadoras de serviços para eventos com profissionais tais como: organizador, promotor e prestador de serviços para eventos.

O Brasil ocupa lugar de destaque no ranking da International Congress and Convention Association (ICCA), por ser o primeiro país latino-americano a estar entre países do mundo que mais sediam eventos e feiras. Esse destaque do país fica demonstrado pelo crescimento de eventos internacionais realizados no Brasil: em 2001 ocupava a $21^{\mathrm{a}}$. posição, com 59 eventos e avançou para a $7^{\mathrm{a}}$. em 2006, sediando 207 eventos internacionais.

O setor de eventos é uma indústria prestadora de serviços, com pouca tradição no uso de estratégia de negócios e pouca estrutura formal. Demonstrando a importância do setor segundo Piscopo (2004), compreende-se que:

O desenvolvimento de eventos exige uma gestão mais eficiente dos processos de planejamento e execução, para a satisfação das necessidades e desejos dos clientes, associada à otimização dos recursos, condição necessária, entretanto não suficiente, à obtenção de retornos financeiros acima da média do mercado. A dinâmica dos cenários competitivos deixa clara a necessidade de a empresa se posicionar estrategicamente no mercado. Para tanto, é preciso considerar o processo de formulação estratégica de curto e longo prazo, o que envolve as estratégias operacionais, estratégias no nível de negócios e estratégias corporativas. (p. 83)

Outros autores como Bowdin, Allen, O’ttole, Harris e McDonnell (2006) destacam a necessidade da gestão e do planejamento de eventos em todos os seus aspectos incluindo gestão de projetos e marketing estratégico. Desse modo, uma gestão estratégica é um passo necessário para empresas nessa indústria que pensem não somente em um desempenho superior, mas também no seu processo de internacionalização, pois há uma maior complexidade, com a adaptação às características e necessidades locais. A forma de atuação não pode ser unicamente global e replicada nos diversos locais de atuação para uma empresa de eventos que queira se tornar internacional.

Revista Ibero-Americana de Estratégia - RIAE, São Paulo, v. 9, n. 1, p. 04-31, jan./abr. 2010. 
Empreendedorismo e Internacionalização: Um Caso no Setor de Eventos de Gestão

\section{PROCEDIMENTO METODOLÓGICO}

O objetivo desta pesquisa é identificar as estratégias de internacionalização e o perfil empreendedor e suas características empreendedoras adotadas pelo HSM Group a partir de sua criação, no Brasil, em 1987. Buscam-se, dessa forma, conhecer as estratégias para a internacionalização de uma empresa de eventos que possui relacionamentos sólidos com alguns dos maiores palestrantes e executivos da indústria de eventos em gestão.

Conforme a recomendação de Eisenhardt (1989), deve ser feita, a priori, a especificação dos construtos, para a formatação do design inicial da pesquisa. A seção 2 define os conceitos-chave usados nesta pesquisa e permite a operacionalização desses conceitos.

A pesquisa é qualitativa e a opção por estudo de caso único deve-se ao fato de que são raras as pesquisas, no Brasil, sobre internacionalização de empresas de eventos. Nenhum trabalho foi encontrado em sites especializados em buscas de artigos científicos, como no Google Acadêmico (2007), segundo várias combinações de palavras-chave. O mesmo vale para o setor de serviços em que Sacramento (2005) complementa, "O estudo da internacionalização de serviços no Brasil se encontra ainda em fase exploratória. Parte disto se deve ao fato de o índice de internacionalização das empresas brasileiras serem, infelizmente, baixo" (p. 82).

Por se tratar de uma pesquisa empírica que investiga um fenômeno contemporâneo dentro de seu contexto real, especialmente quando os limites entre fenômeno e contexto não estão claramente evidentes (Yin, 1994, p. 13), escolheu-se dentre as modalidades de estratégias qualitativas a de estudo de caso único para realização da pesquisa. Dentre os fatores para a escolha do HSM Group tem-se: ser uma empresa multinacional reconhecida em sua área de atuação; ser de um setor intensivo em conhecimento e ter sua origem no Brasil.

Dentre as principais fontes secundárias têm-se informações e dados a partir de consulta aos diversos sites corporativos (www.gestion.com, www.hsmglobal.com, www.hsm.com.br, www.managementv.com, etc.), jornais diários como o Argentino La Nación e artigos de periódicos, anais de congressos e eventos científicos, relatórios de pesquisa, dissertações. Destaca-se a literatura focada em empreendedorismo, negócios internacionais e internacionalização de serviços e eventos.

As fontes primárias tiveram início em consulta à assessoria de imprensa da HSM no Brasil e uma primeira entrevista semiestruturada foi realizada por telefone, sendo respondente o gerente dessa assessoria. Seguiram-se novos contatos até que se completassem as informações necessárias. Essas entrevistas foram realizadas no início de outubro de 2007. Em março de 2008 foram obtidas

Revista Ibero-Americana de Estratégia - RIAE, São Paulo, v. 9, n. 1, p. 04-31, jan./abr. 2010. 
informações adicionais sobre a atuação da HSM por meio de colaboradores brasileiros e argentinos com a intermediação de empresa internacional de consultoria em alta-gestão em seu escritório de Buenos Aires, Argentina. Essas entrevistas semiestruturadas foram realizadas por e-mail e outras por telefone com duração entre 15 minutos e 20 minutos cada uma.

\section{O CASO HSM GROUP}

A HSM Group é uma empresa de origem brasileira, com presença internacional, líder em produtos de capacitação de executivos. Dentre suas atividades, realiza conferências (fóruns e seminários), disponibiliza conteúdo on-line e publica revistas de gestão. Desse modo, o foco central da HSM é prover conteúdo de gestão para executivos.

Por ser uma empresa global, a HSM fez um reposicionamento de sua imagem com a definição de uma nova identidade visual, criando o conceito "inspiring ideas". A expressão foi incorporada à sua logomarca e, segundo a HSM Group, o que move o mundo, e o ser humano, é a inspiração, e a partir desse eixo condutor a organização desenvolve seus negócios, com o intuito de que os produtos tendem a inspirar ao executivo, a dar-lhe ideias de força, a ajudar-lhe a levar adiante essas ideias. Para tanto, a própria organização baseia-se em três ideias inovadoras, que lhes permitem criar com tranquilidade, que são: o inconformismo, a diversidade e o rigor.

A história da HSM começa no Brasil em 1987 quando três amigos têm a ideia de trazer os maiores nomes da gestão mundial para seminários de um dia, formato pioneiro na época. $\mathrm{O}$ primeiro evento organizado pela HSM no Brasil teve Richard Copaken como palestrante principal. Temas como franchising e alta performance, por exemplo, foram lançados no país em eventos da HSM. Nomes como Don Peppers, Al Ries, Philip Kotler, Michael Porter, Ram Charan e Tom Peters vieram ao Brasil pela primeira vez por meio da HSM.

A ideia dos seminários de um dia deu certo, porém o formato deixou de atender à demanda dos executivos brasileiros por conhecimento especializado em management. Nessa direção, a HSM passou a organizar fóruns com duração de dois dias, nos quais diversos "gurus" discorrem sobre o mesmo tema, mas com abordagens diferentes.

Os eventos realizados pela empresa começaram a repercutir fora do Brasil. Na Argentina, três amigos, Nelson Dubosq, Tristán Bareiro e Eduardo Bruchou, engenheiros que, em 1992, deixaram a empresa em que trabalhavam havia mais de dez anos, a Impregilo italiana, líder no setor de construção civil, baseada próxima a Milão, e passaram a oferecer eventos de negócios

Revista Ibero-Americana de Estratégia - RIAE, São Paulo, v. 9, n. 1, p. 04-31, jan./abr. 2010. 
Empreendedorismo e Internacionalização: Um Caso no Setor de Eventos de Gestão

concomitantes aos da HSM no Brasil, e, em 1993, interessados em implantar o conceito HSM de organizar conferências empresariais na Argentina, dois grupos locais propuseram sociedade para os sócios brasileiros. Desse modo, tem início a internacionalização da HSM em seus primeiros passos.

Ate aqui o processo de internacionalização da HSM segue os passos da Escola de Uppsala (Johansson \& Vahlne, 1977) em relação à cadeia de estabelecimento e também à distância psíquica, e de modo complementar, a revisão do modelo (Johansson \& Vahlne, 2009) em relação às redes de negócios e ao desenvolvimento de competências, confiança e reputação. É importante destacar que atuavam na Argentina, em 1993, empresas como a Chilena Seminarium e a norte-americana American Management Association (AMA) em eventos de gestão.

A AMA norte-americana era competidora na Argentina, em 1993, e atualmente tem uma rede que atua, além dos EUA, no México, na Ásia-Pacífico, Canadá, Europa (baseada na Bélgica), no Oriente Médio e na África. É um exemplo de competidor da HSM para diversos formatos de eventos, mas não para megaeventos. Soube, portanto, aproveitar espaços mesmo com competidores fortes presentes em seu território.

Dois anos após o desembarque na Argentina, a operação daquele país resolve expandir a atuação como provedora de conteúdo exclusivo sobre management e lança, em 1995, a revista Gestión. A publicação chega ao Brasil em 1996 com o nome de HSM Management. Aqui, novamente, outra demonstração do desenvolvimento de competências intragrupo necessária ao processo de internacionalização.

Nos anos seguintes, consolida-se como uma empresa de conteúdo multimídia de management, que é transmitido para a comunidade executiva por meio de conferências, fóruns e seminários, de publicações impressas e on-line, fornecendo conteúdo multimídia, no qual são apresentados site on-line, publicação de revistas e de canal de TV por assinatura.

Em 1997 os argentinos compraram a parte dos brasileiros, conservando o nome HSM. O ano de 1998 marca a entrada da HSM no calendário das maiores conferências do mundo por meio da primeira ExpoManagement realizada na Argentina. O evento passa a ser organizado no Brasil em 2001.

Revista Ibero-Americana de Estratégia - RIAE, São Paulo, v. 9, n. 1, p. 04-31, jan./abr. 2010. 
Belmiro do Nascimento João, João Gonçalves Monteiro Jr, Aparecida Honório Dias \& Fabrício César Bastos

Figura 1 - O Processo de Internacionalização da HSM Group.

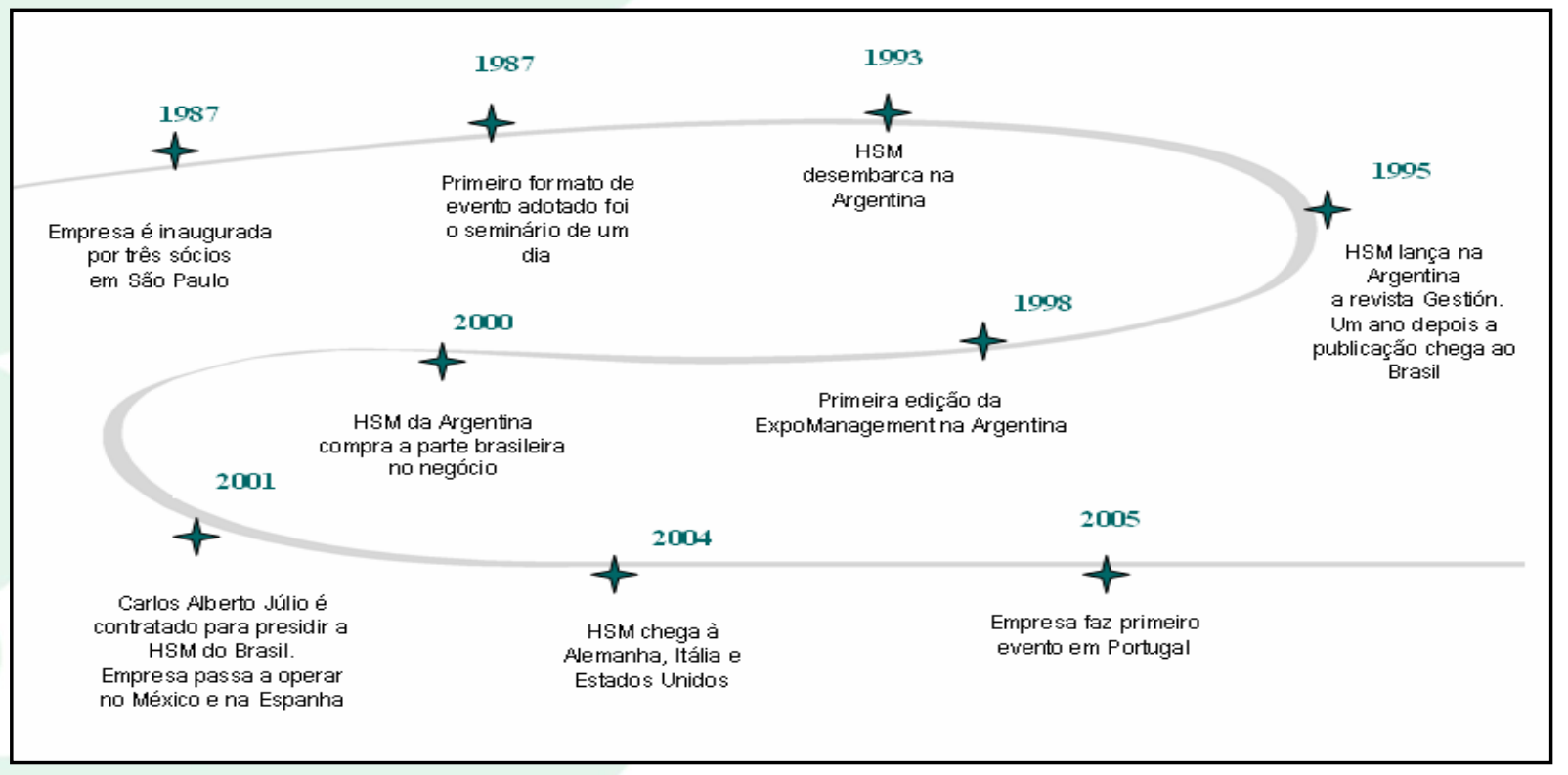

Fonte: Elaboração própria a partir de dados da HSM Brasil.

Nesse período, anos 2000, ocorre uma nova injeção de capital na companhia. Quatro grupos passam a controlar o negócio: Diário La Nacion, Management Team, J.P.Morgan e o Credit Suisse First Boston (CSFB). O investimento dá condições para uma expansão global. Assim, entre 2001 e 2004, a HSM monta operações no México, na Espanha, Itália, Alemanha, nos EUA e em Portugal, totalizando oito países com mais de 300 mil clientes, que atuam em cerca de 80 mil empresas em todo o mundo. Essa evolução do processo de internacionalização e seus principais eventos são resumidos na Figura 1. Novamente fica evidenciada a conformidade com o Modelo de Uppsala em relação à cadeia de estabelecimento e à distância psíquica (Johansson \& Vahlne, 1977) e às redes de negócios (Johansson \& Vahlne, 2009).

Adota, desse modo, a lógica de uma empresa internacionalizada que desenvolve e deve compartilhar conhecimento entre suas diversas unidades. Atualmente, a HSM adota um modelo holográfico de gestão. Cada unidade representa um todo. A operação brasileira, por exemplo, montou as operações no México e nos EUA. A área de tecnologia da Argentina serve de paradigma para todas as demais bases. Já o conteúdo é principalmente desenvolvido no Brasil. Dentre os funcionários, a operação global conta com 300, sendo 80 deles no Brasil.

Revista Ibero-Americana de Estratégia - RIAE, São Paulo, v. 9, n. 1, p. 04-31, jan./abr. 2010. 
Empreendedorismo e Internacionalização: Um Caso no Setor de Eventos de Gestão

Tabela 1- Número de Eventos, Palestrantes e Cidades.

\begin{tabular}{|c|c|c|c|c|}
\hline EVENTOS & 2003 & 2004 & 2005 & 2006 \\
\hline NÚMERO & 12 & 25 & 29 & 40 \\
\hline PALESTRANTES & 44 & 63 & 70 & 150 \\
\hline \multirow[t]{16}{*}{ CIDADES } & 4 & 9 & 11 & 15 \\
\hline & Buenos Aires & Buenos Aires & Buenos Aires & Buenos Aires \\
\hline & São Paulo & São Paulo & São Paulo & São Paulo \\
\hline & Cid. do México & Cid. do México & Cid. do México & Cid. do México \\
\hline & Madri & Madri & Madri & Madri \\
\hline & & Chicago & Nova York & Chicago \\
\hline & & Nova York & Barcelona & Nova York \\
\hline & & Barcelona & Frankfurt & Barcelona \\
\hline & & Frankfurt & Milão & Frankfurt \\
\hline & & Milão & Munique & Milão \\
\hline & & & Los Angeles & Munique \\
\hline & & & Lisboa & Lisboa \\
\hline & & & & Boston \\
\hline & & & & Zaragoza \\
\hline & & & & Sevilha \\
\hline & & & & Monterrey \\
\hline
\end{tabular}

Fonte: Dados Internos. HSM Brasil, 2007.

Revista Ibero-Americana de Estratégia - RIAE, São Paulo, v. 9, n. 1, p. 04-31, jan./abr. 2010. 
A Tabela 1 apresenta a evolução dos eventos de 12 para 40, no período entre 2003 e 2006, do número de palestrantes de 44 para 150, no mesmo período. Outro aspecto é o do número de cidades (de quatro para 15) nos oito países nos quais a HSM Group atua.

O portfólio dos principais produtos (ou formatos) das áreas de negócios (ou eventos) da HSM Group são:

A ExpoManagement, a qual foi criada em 1998, na Argentina e, em 2001, aperfeiçoada no Brasil. Atualmente o evento também é organizado no México e na Espanha. A ExpoManagement é um megaevento, um dos maiores encontros de executivos do mundo, e o principal formato da HSM, com três dias de evento. Em 2006 foram mais de 4,5 mil executivos participando da edição brasileira com cerca de 18 mil visitações. Mais de dez renomados especialistas apresentam os principais temas em gestão empresarial na área do Auditório Principal. Já a área de exposição é um espaço interativo,

com ciclos de palestras e praças temáticas com estandes de soluções em gestão de vendas, pessoas, conhecimento e empreendedorismo. Nesse espaço há também palestras paralelas em um total de cerca de 180 palestras em auditórios temáticos.

Os Fóruns Mundiais apresentam um formato de evento de dois dias dedicados a um assunto específico do management, com especialistas internacionais e do país anfitrião do Fórum Mundial, e abordam temas como marketing, vendas, alta performance e negociação. No Brasil o primeiro evento da série foi o Fórum Mundial de Alta Performance, realizado em 2006.

Os Special Management Programs são eventos que permitem uma maior interação entre os participantes e o palestrante. Foi desenvolvido em um formato que lembra uma sala de aula, e desse modo recebe professores e consultores internacionais do management, que abordam somente temas específicos com dois dias de duração. Exemplos de nomes envolvidos nesse formato são Ram Charan, John Davis e Philip Kotler. A “sala de aula” tem, no máximo, 150 participantes.

As revistas de gestão compreendem a Gestión, em espanhol, e a HSM Management, em português e espanhol (Espanha), que estão entre as mais importantes publicações de gestão de países como Brasil, Argentina, Chile, Colômbia, Peru, México e Espanha. A revista traz prioritariamente artigos traduzidos e adaptados de publicações acadêmicas, executivas e de consultorias internacionais como a Harvard Management Update, MIT Sloan Management Review, Strategy \& Leadership, Fast Company, The McKinsey Quartely, Business Strategy Review entre outras. Entre os principais autores a assinarem os artigos tem-se: Jack Welsh, Philip Kotler, Kenichi Ohmae, Michael Hammerr, Willian Ury, W. Cham Kim e Alvin Toffler.

Revista Ibero-Americana de Estratégia - RIAE, São Paulo, v. 9, n. 1, p. 04-31, jan./abr. 2010. 
A Management TV é um novo formato de produto disponibilizado por assinatura de TV a cabo, Multicanal e Cablevisión, na Argentina, e no Brasil pela Sky (canal 93), desde 2007. Trata-se de um canal de programação de gestão executiva veiculado 24 horas por dia. A empresa aproveita estrategicamente todo seu know-how adquirido e o feeback da sua comunidade global de clientes para criar a programação que é dividida por sessões tais como: líderes, publicidade e marketing, talk shows (por exemplo: The Charlie Rose Show), Reality Shows, Marcas, mercados e clientes, esportes e management, empreendedores, PME (pequenas e médias empresas), empresa, futuro e tendências, e por fim indústria. Para a HSM, a capacitação das universidades, das escolas de negócios, das conferências e dos livros é insubstituível, mas não há nada como ver, e ouvir, de primeira mão, dos que pensam, antecipam-se, criam, trabalham, aspiram e procuram diariamente o sucesso. Essa é uma das aspirações do canal de TV.

O Site da HSM disponibiliza conteúdo on-line de artigos e reportagens de renomadas universidades, com foco em temas como estratégia, empreendedorismo, marketing, vendas, gestão de pessoas, gestão de carreira e tecnologia e entrevistas com executivos. Disponibiliza também diversas newsletters.

Ficou evidenciado dessa forma que, concomitante ao processo de internacionalização, o desenvolvimento de competências inclui a consolidação de sua rede de negócios e o de sua reputação (Johansson \& Vahlne, 2009) e evidenciado para empresas de serviços por Lowendahl (2000). Procurou-se, assim, apresentar não somente os seus produtos e serviços, mas a capacidade de vislumbrar as necessidades do seu público-alvo, dando-lhe uma identidade e vantagem competitiva em um setor baseado no conhecimento. Essas vantagens apresentam o conceito proposto por Dunning $(1980,1988)$ no desenvolvimento do paradigma OLI e apresentado, para o setor de serviços, por Chryssochoidis et al. (1997).

\section{ANÁLISE DO CASO}

Marco importante a ser observado é o processo de "refundação" a partir do controle total dos gestores argentinos. O papel empreendedor passa a ser exercido por Nelson Duboscq (CEO) e Eduardo Bruchou (CEO América Latina), e ressalta também a participação de todos os números um de cada país nas reuniões realizadas no processo formal de planejamento. Um exemplo desse espírito empreendedor, no caso do Brasil, é a figura do seu cofundador José Salibi Neto, que teve seus estudos em universidades americanas incluindo a turma de MIBS (Master of International Business Studies) de 1986 da Universidade da Carolina do Sul. Outro exemplo é seu ex-presidente,

Revista Ibero-Americana de Estratégia - RIAE, São Paulo, v. 9, n. 1, p. 04-31, jan./abr. 2010. 
Belmiro do Nascimento João, João Gonçalves Monteiro Jr, Aparecida Honório Dias \& Fabrício

César Bastos

no Brasil, Carlos Alberto Júlio que figura como professor universitário, palestrante e autor de livros de gestão e é graduado em Administração de Empresas com especialização na Harvard Business School e no IMD de Lausanne-Suíça.

A HSM soube aproveitar o desenvolvimento de suas competências essenciais (Prahalad \& Hamel, 1990), como identificar e antecipar necessidades de informação em diferentes formatos para o público executivo. De outra forma, soube identificar o conhecimento criado localmente e disseminá-lo por toda a corporação. A Revista Gestión é um exemplo, assim como a ExpoManagement, que surgiu na Argentina e foi replicado para outros países. No caso da Revista Gestión, que teve seu primeiro número lançado na Argentina em fevereiro de 1996, seguiu-se o lançamento no Brasil da HSM Management em março/abril de 1997, com artigos comuns à primeira edição da Gestión, a exemplo do "Nuevas formas de gerencia", no original e traduzido como "Novas formas de gerenciar" assinado por Christopher Bartlett e Sumantra Ghoshal e, de outro artigo, "La empresa del 2020" traduzido como “A empresa do ano 2020" e assinado por Peter Senge, Thomas Malone e Walter Kiechel.

A empresa soube aproveitar uma rede de relacionamentos forte, já que congrega nomes de destaque na realização de seus serviços. Tem-se, por exemplo, entre outras personalidades do mundo político e de negócios confirmados como palestrantes em 2008 Tony Blair, Jim Collins, Colin Powell, Madeleine Albright, Jack Welch, Michael Porter, Muhammad Yunus, John Chambers, Antoine Van Agtmael, Roger Agnelli, Francis Ford Coppola, Jack Welch, C.K. Prahalad e Alan Greenspan.

Nota-se uma preocupação muito grande com a estratégia corporativa, contrastando com a especificidade da estrutura de um setor normalmente pouco estruturado. O processo formal de planejamento é realizado por meio de reuniões semestrais com todos os gestores principais de cada país, reuniões estas com duração entre três e quatro dias. Disso se denota a montagem de redes e o desenvolvimento de sua reputação e seus relacionamentos como competência essencial.

De algum modo a HSM Group segue o modelo incremental da Escola de Uppsala (Johansson \& Vahlne, 1977), ao analisar sua evolução a partir de Brasil (1987), Argentina, México, Espanha, Alemanha, Itália, Estados Unidos e Portugal. É bom destacar que temos dois polos para a determinação da distância psíquica, ou seja, Brasil e Argentina, e que esta última, por exemplo, tem em seus "fundadores" uma grande proximidade com a Itália, pois atuaram em construtora italiana por uma década. O exemplo da ExpoManagement é típico, criada na Argentina (1998), aperfeiçoada no Brasil e realizada no México e na Espanha. Durante a recente crise e recessão argentina (entre

Revista Ibero-Americana de Estratégia - RIAE, São Paulo, v. 9, n. 1, p. 04-31, jan./abr. 2010. 
2002 e 2005), a ExpoManagement deixou de ser ali realizada, retornando em 2006 mas, nesse período, foi realizada em outros países, como o Brasil, o que é uma vantagem para uma empresa internacionalizada, pois é um evento que exige investimentos da ordem de US\$ 2 milhões. Em relação à Management TV ocorre o mesmo, o lançamento e sua base operacional é a Argentina, mas com a vocação para inserir conteúdos locais. A participação em redes (Johansson \& Vahlne, 2009) e a gestão dos seus relacionamentos influenciam significativamente em suas atividades, por exemplo, ao apresentar o mesmo conjunto de palestrantes internacionais em vários de seus eventos pelo mundo e a replicação de conteúdo em vários formatos multimídia.

A dinâmica do empreendedorismo da HSM também pode ser vista na tentativa de conquistar novos espaços com eventos como o World Science Forum, um encontro de ciências, ocorrido entre 8 e 9 de novembro de 2006 em Nova York. Foi sua primeira tentativa de realizar um evento fora da área do Management e contou com a parceria da Revista Scientific America.

A análise do tipo de empreendedor para a HSM em relação ao modelo de Andersson (2000) pode ser classificada com características do empreendedor de marketing e do estrutural. O tipo de empreendedor estrutural é justificado pela postura da empresa de criar um novo segmento de negócios em relação aos seus competidores, já o empreendedor de marketing busca novos mercados, visto que esse tipo de empreendedor busca ser inovador em outras formas, por exemplo, empregar novos processos de marketing como novos métodos de distribuição em novos mercados. Desse modo, e segundo a tipologia de Andersson (2000), a HSM pode ser classificada inicialmente como uma organização empreendedora estrutural e que migra para uma empreendedora de marketing.

Há planos de entrada no mercado asiático, mas, por enquanto, a HSM amplia sua participação nos mercados em que atua. Entre os planos tem-se a Management TV nos EUA e o conteúdo das revistas em língua inglesa para uma maior projeção internacional.

\section{CONCLUSÃO}

A presente pesquisa permitiu o contato com um caso real de internacionalização de uma empresa de origem brasileira em um setor pouco estudado. A trajetória de expansão e de internacionalização é indicadora da capacidade empreendedora daqueles envolvidos no desenvolvimento da HSM, sejam os fundadores brasileiros ou seus pares argentinos, após sua "refundação". Um projeto de negócios inovador, que explorou oportunidades e que por meio de

Revista Ibero-Americana de Estratégia - RIAE, São Paulo, v. 9, n. 1, p. 04-31, jan./abr. 2010. 
parcerias e relacionamentos, retrata um processo de internacionalização bem-sucedido de uma empresa já estabelecida.

Na experiência de internacionalização da empresa, depreende-se uma postura proativa, a capacidade de correr riscos, sua busca por inovações, subjacentes a sua experiência ao longo de duas décadas, que dão corpo ao perfil empreendedor dos seus gestores. Portanto, alinha-se ao conceito de empreendedor de marketing, como proposto por Andersson (2000) em sua forma atual e na sua forma inicial de empreendedor estrutural.

A empresa apresentou os postulados do modelo de internacionalização de Uppsala tanto em seu formato original (Johansson \& Vahlne, 1977) quanto em seu modelo atual (Johansson \& Vahlne, 2009), isso se deve ao fato de atuar em um setor dinâmico e de internacionalização mais complexa.

A presente pesquisa apresenta suas limitações pela própria abordagem metodológica adotada, ou seja, o estudo de caso. Limitando-se a fontes secundárias e poucas fontes primárias envolvendo a unidade brasileira e a argentina, devendo-se expandir para trabalhos futuros.

Diversas direções podem ser seguidas por pesquisas futuras. Os fluxos de conhecimento entre subsidiárias é um destaque, a formação de alianças e redes de negócios, outra possibilidade. Uma pesquisa específica utilizando-se outra unidade de análise que não a organização também é possível.

Com a elaboração desta pesquisa, o artigo pretende ter contribuído para a literatura brasileira de internacionalização, atuando no sensível setor de serviços e eventos.

\section{REFERÊNCIAS}

Acs, Z., Dana, L. \& Jones, M. V. (2003). Toward new horizons: the internationalization of entrepreneurship. Journal of International Entrepreneurship, 1(1), 5-12.

http://dx.doi.org/10.1023/A:1023257414794

Andersson, S. (2000). The internationalization of the firm from an entrepreneurial perspective. International Studies of Management and Organization. Spring, 30, 65-94.

Arvidsson, N. (1997). Internationalization of service firms: strategic considerations. In: Chryssochoidis, G., Millar \& C., Clegg, J. (Ed.). Internationalization Strategies (Academy of International Business). New York: Palgrave Macmillan.

Revista Ibero-Americana de Estratégia - RIAE, São Paulo, v. 9, n. 1, p. 04-31, jan./abr. 2010. 
Empreendedorismo e Internacionalização: Um Caso no Setor de Eventos de Gestão

Associação de Marketing Promocional [Ampro]. (2008). Recuperado em 8 de abril de 2008, de http://www.ampro.com.br

Balmer, J. M. T. \& Greyser. S. A. (2006). Corporate marketing integrating corporate identity, corporate branding, corporate communications, corporate image and corporate reputation. European Journal of Marketing. 40(7/8), 730-741.

http://dx.doi.org/10.1108/03090560610669964

Bowdin, G., Allen, J., O'toole, W., Harris, R. \& McDonnell, I. (2006). Events management (2nd. ed.). Newton: Butterworth-Heinemann.

Brønn, P. S. (2007). Relationship outcomes as determinants of reputation. Corporate Communications: An International Journal. 12(4), 376-393.

http://dx.doi.org/10.1108/13563280710832524

Buckley, Peter J., Pass, C. L. \& Prescott, K. (1992). The internationalization of service firms: a comparison with the manufacturing sector. Scandinavian International Business Review, 1(1), $39-56$.

http://dx.doi.org/10.1016/0962-9262(92)90028-5

http://dx.doi.org/10.1016/0962-9262(92)90035-5

Britto, J. \& Fontes, N. (2002). Estratégias para eventos: uma ótica do marketing e do turismo. São Paulo: Aleph.

Casson, M. (1997). Entrepreneurial networks in international business. Business \& Economic History, 26, 811-823.

Cerqueira, A. H. F. \& Quadros, R. (2003). O processo de internacionalização dos serviços: um enfoque nos serviços produtivos intensivos em conhecimento. In. São Paulo, IV Iberoamerican Academy of Management Proceedings.

Chryssochoidis, G., Millar, C. \& Clegg, J. (1997). Internationalization strategies (Academy of International Business). New York: Palgrave Macmillan.

Dana, L. (Org.). (2006). Handbook of research on international entrepreneurship. Northampton: Edward Elgar Publishing.

Degen, R. (1989). O empreendedor: fundamentos da iniciativa empresarial. São Paulo: McGrawHill.

Dornelas, J. (2003). Empreededorismo corporativo: como ser empreendedor, inovar e se diferenciar em organizações estabelecidas. Rio de Janeiro: Elsevier.

Dornelas, J. (2007). Empreendedorismo na Prática. Rio de Janeiro: Elsevier.

Revista Ibero-Americana de Estratégia - RIAE, São Paulo, v. 9, n. 1, p. 04-31, jan./abr. 2010. 
Dunning, J. (1980). Toward an eclectic theory of international production: some empirical tests. Journal of International Business Studies, 11(1), 9-31.

http://dx.doi.org/10.1057/palgrave.jibs.8490593

Dunning, J. (1988). The eclectic paradigm of international production: a restatement and some possible extensions. Journal of International Business Studies, 19(1), 1-31.

http://dx.doi.org/10.1057/palgrave.jibs.8490372

Eisenhardt, K. (1989). Building theories from case study research. Academy of Management Review, 14(4), 532-550.

http://dx.doi.org/10.2307/258557

http://dx.doi.org/10.5465/AMR.1989.4308385

Fombrun, C. J. (1996). Reputation: realizing value from the corporate image. Boston: Harvard Business School Press.

Fombrun, C. J. \& Van Riel, C. B. M. (2003). Fame and fortune: how successful companies build winning reputations. Upper Saddle River: FT Prentice-Hall.

Goerzen, A. \& Makino, S. (2007). Multinational corporation internationalization in the service sector: a study of Japanese trading companies. Journal of International Business Studies, 38, 1149-1169.

http://dx.doi.org/10.1057/palgrave.jibs.8400310

Google Acadêmico. (2007). Recuperado em 15 de setembro de 2007 de, academico.google.com.br

Hammer, M. \& Champy, J. (1994). Reengenharia. Rio de Janeiro: Campus.

Hitt, M. A., Hoskisson, R. E. \& Ireland, R. D. (2002). Administração Estratégica. São Paulo: Editora Thomson Learning.

Hitt, M. A., Ireland, R. D., Camp, S. M. \& Sexton, D. L. (2002). Strategic entrepreneurship: creating a new mindset. Malden: Blackwell Publishing.

Johanson, J. \& Sharma, D. (1987). Technical consultancy in internationalization. International Marketing Review, 4, 20-29. http://dx.doi.org/10.1108/eb008339

Johanson, J. \& Mattsson, L. (1988). Internationalization in industrial systems: a network approach. In: Hood, H. \& Vahlne, J. (Eds.). Strategies in foreign competition. London: CroomHelm.

Johanson, J. \& Vahlne, J. (1977). The internationalization process of the firm: a model of knowledge development and increasing market commitment. Journal of International Business Studies, 8 Spring/Summer.

Revista Ibero-Americana de Estratégia - RIAE, São Paulo, v. 9, n. 1, p. 04-31, jan./abr. 2010. 
Empreendedorismo e Internacionalização: Um Caso no Setor de Eventos de Gestão

Johanson, J. \& Vahlne, J. (1990). The mechanism of internationalization. International Marketing Review, 8(4), 11-24.

Johanson, J. \& Vahlne, J. (2009). The Uppsala internationalization process revisited: from liability of foreigness to liability of outsidership. Journal of International Business Studies, 40: 11411431.

http://dx.doi.org/10.1057/jibs.2009.24

Knight, A., Rialp A. \& Rialp, J. (2005). The phenomenon of early internationalizing firms: what do we know after a decade (1993-2003) of scientific inquiry?. International Business Review, 14(2), $147-166$.

Knight, G. A. \& Cavusgil S. T. (1996). The Born Global Firm: A challenge to traditional internationalization theory. Advances in International Marketing, (8), 11-26.

http://dx.doi.org/10.1016/j.ibusrev.2004.04.006

Kogut, B. \& Zander, U. (1992). Knowledge of the firm, combinative capabilities, and the replication of technology. Organization Science, 3(3), 383-397.

http://dx.doi.org/10.1287/orsc.3.3.383

Lovelock, C. \& Wright, L. (2002). Serviços: marketing e gestão. São Paulo: Saraiva.

Lowendahl, B. R. (2000). Strategic management of professional service firms (2nd ed.). Copenhagen: Copenhagen Business School Press.

Maximiano, A. (2007). Administração para empreendedores: fundamentos da criação e da gestão de novos negócios. São Paulo: Pearson Prentice-Hall.

Mazzola, H. J. (2006). Estratégias de internacionalização em serviços de engenharia intensivos em conhecimento. Workshop sobre Internacionalização de Empresas São Paulo: USP. Maio.

McDougall, P. P., Shane, S. \& Oviatt, B. M. (1994). Explaining the formation of international new ventures. Journal of Business Venturing, 9, 469-487.

http://dx.doi.org/10.1016/0883-9026(94)90017-5

McDougall, P. P. \& Oviatt, B. M. (2000). International entrepreneurship: the intersection of two research paths. Academy of Management Journal, 43(5), 902-906.

http://dx.doi.org/10.2307/1556418

McDougall, P. P. \& Oviatt, B. M., Shrader, R. C. (2003). A comparison of international and domestic new ventures. Journal of International Entrepreneurship. 1(1), 59-82.

http://dx.doi.org/10.1023/A:1023246622972

Revista Ibero-Americana de Estratégia - RIAE, São Paulo, v. 9, n. 1, p. 04-31, jan./abr. 2010. 
Belmiro do Nascimento João, João Gonçalves Monteiro Jr, Aparecida Honório Dias \& Fabrício César Bastos

Oviatt, B. M., McDougall, P. P. (Org.). (2006). International entrepreneurship. Northampton: Edward Elgar Publishing.

Peters, T. J. \& Waterman, R. H. (1982). In search of excellence: lessons from America's best run companies. London: Harper \& Row.

Piscopo, M. R. (2004). Estratégias das empresas organizadoras de eventos nos anos 2000: um estudo exploratório da indústria paulistana de eventos. Dissertação de mestrado em Administração. Pontifícia Universidade Católica de São Paulo, São Paulo, Brasil.

Prahalad, C. K. \& Hamel, G. (1990). The core competence in the corporation. Harvard Business Review, 79-91.

Ricks, D. A. \& Wright, R. W. (1994). Trends in international business research: twenty-five years later. Journal of International Business Studies, 25.

Sacramento, I. C. (2005). Motivos, Formação de Redes e Direção da Internacionalização de Escolas de negócios do Brasil e da América Latina: estudos de casos. Tese de doutorado. Universidade Federal do Rio de Janeiro, Instituto COPPEAD, Rio de Janeiro, Brasil.

Silva Neto, J. B. \& Paula, G. M. (2005). Internacionalização de serviços: uma análise de empresas líderes no mercado mundial de serviços de call center. In. $5^{\circ}$. Workshop de Internacionalização. Rio de Janeiro: Coppead.

The United Nations Centre on Transnational Corporations [UNCTC]. (2007). Recuperado em 11 de outubro de 2007, de http//:unctc.unctad.org

Wood, T., Jr., \& Paula, A. P. P. (2002). Pop-management: pesquisa sobre as revistas populares de gestão no Brasil. In: Encontro Nacional dos Programas de Pós-Graduação em Administração, 26, Salvador, Anais... [S.I.]: 2002. CD-ROM.

Yeung, H. W. (2002). Entrepreneurship in international business: an institutional perspective. Asia Pacific Journal of Management, 19(1), 29-61.

Yin, R. K. (1994). Case study research, design and methods (2nd. ed.). Beverly Hills: Sage Publications. http://dx.doi.org/10.1023/A:1014887523110

Zahra, S. A. \& George, G. (2002). International entrepreneurship: the current status of the field and future research agenda. In.: Hitt, M. A., Ireland, R. D., Camp, S. M. \& Sexton, D. L. Strategic Entrepreneurship: creating a new mindset. Blackwell Publishing.

Revista Ibero-Americana de Estratégia - RIAE, São Paulo, v. 9, n. 1, p. 04-31, jan./abr. 2010. 
Recebido: 15/11/2009

Aprovado: 20/01/2010

Revista Ibero-Americana de Estratégia - RIAE, São Paulo, v. 9, n. 1, p. 04-31, jan./abr. 2010. 